\title{
Perspectives on death and dying: a study of resident comfort with End-of-life care
}

\author{
Jessica M. Schmit ${ }^{*}$, Lynne E. Meyer ${ }^{2}$, Jennifer M. Duff ${ }^{1}$, Yunfeng Dai $^{3}$, Fei Zou ${ }^{3}$ and Julia L. Close ${ }^{1}$
}

\begin{abstract}
Background: Despite the benefits to early palliative care in the treatment of terminal illness, barriers to timely hospice referrals exist. Physicians who are more comfortable having end-of-life (EOL) conversations are more likely to refer to hospice. However, very little is known about what factors influence comfort with EOL care.

Methods: An anonymous survey was sent to all the residents and fellows at a single institution. Self-reported education, experience and comfort with EOL care was assessed. Using multivariate logistic regression analysis, variables that influenced comfort with EOL conversations were analyzed.
\end{abstract}

Results: Most residents (88.1\%) reported little to no classroom training on EOL care during residency. EOL conversations during residency were frequent (50.6\% reported $>10)$ and mostly unsupervised (61.9\%). In contrast, EOL conversations during medical school were infrequent (3.7\% reported $>10)$ and mostly supervised (78.6\%). Most (54.3\%) reported little to no classroom training on EOL care during medical school. Physicians that reported receiving education on EOL conversations during residency and those who had frequent $E O L$ conversations during residency had significantly higher comfort levels having EOL conversations ( $p=0.017$ and $p=0.003$, respectively). Likewise, residents that felt adequately prepared to have EOL conversations when graduating from medical school were more likely to feel comfortable $(p=0.030)$.

Conclusions: Most residents had inadequate education in EOL conversation skills during medical school and residency. Despite the lack of training, EOL conversations during residency are common and often unsupervised. Those who reported more classroom training during residency on EOL skills had greater comfort with EOL conversations. Training programs should provide palliative care education to all physicians during residency and fellowship, especially for those specialties that are most likely to encounter patients with advanced terminal disease.

Keywords: Graduate Medical Education, End of life care, Terminal Care, Internship and Residency, Palliative Care

\section{Background}

Studies have shown the benefits of involving palliative care early in the care of patients with terminal disease. Implementation of palliative care in addition to usual care improves patient survival, [1-3] decreases health care costs, [4-6] and improves patients' and caregivers' quality of life (QOL) [2, 7-10]. Despite this, hospice and palliative care services are underutilized, [11] with studies demonstrating that up to $50-55 \%$ of terminally ill, hospice eligible patients are never referred by their treating physician $[12,13]$.

\footnotetext{
* Correspondence: Jessica.Schmit@medicine.ufl.edu

'Department of Medicine, Division of Hematology and Oncology, University of Florida, 1600 SW Archer Rd, 32610 Gainesville, FL, USA

Full list of author information is available at the end of the article
}

There are many barriers to appropriate and timely hospice referrals, arising from the patient, health care system or physicians [14]. Patients and their caregivers may have difficulty accepting the illness as terminal. They may also fear hospice enrollment or may not understand the benefits to hospice care $[7,15,16]$. Patient age, gender and race are known to influence hospice utilization [17-20]. Furthermore, the health care system has often limited hospice eligibility to those with an estimated life-expectancy of 6 months or less, forcing patients to choose between a curative versus hospice approach to their care $[16,21]$. Physicians often delay discussing hospice and palliative care until late in the disease course $[22,23]$. They may assume that patients or their families do not wish to know about hospice or 
are unwilling to accept it [12, 24-26]. They also may have misconceptions about eligibility criteria or services offered by hospice [12, 16, 21]. Lastly, physicians may delay discussing hospice and palliative care as to avoid uncomfortable conversations and emotions [26, 27].

Although much is known about potential barriers to hospice referrals, very little is known about what determines physician comfort with end-of-life (EOL) conversations and dying patients. A study by Kogan et al. demonstrated that physicians who are comfortable discussing end-of-life care issues are more likely to refer to hospice [28]. By identifying what factors influence physician comfort, it may be possible to implement changes that can lead to more timely hospice referrals, lessaggressive care at the EOL and better QOL for patients. In the present study, we aimed to better understand the factors that may influence physician comfort with EOL care. We hypothesized that physician demographics, spirituality and education/experience may all play a role in comfort with EOL care.

\section{Methods}

In February 2015, a survey was sent electronically to all the residents and fellows $(n=787)$ at a single academic institution. They were asked to participate in a survey assessing their comfort with caring for dying patients and EOL issues. A copy of the informed consent was provided along with a link to the survey. Participation was voluntary and results were anonymous. The study design, survey questions, and consent process were approved by the Institutional Review Board. The online survey consisted of a total of 33 questions (see Additional file 1 for a full list of questions and answer choices) and was conducted using Qualtrics $^{\mathrm{Tw}}$ software. Statistical analysis was performed using SPSS version 22 and SAS version 9.4 software.

To assess comfort, participants were queried as to how comfortable they felt having EOL conversations with patients and families using a five-point Likert scale with choices ranging from "very uncomfortable" to "very comfortable". Answer choices were reverse coded for analysis with a score of 5 being most comfortable and 1 being least comfortable.

To assess pairwise relationship between each pair of collected variables, we used 1) Spearman's rank correlation coefficient for all questions with ranked variable pairs, 2) the Mann-Whitney test or the Kruskal-Wallis test for ranked variable and nominal variable pairs, and 3) a chi-square test or Fisher's exact test for all nonranked variable pairs. Logistic regression analysis was used to independently evaluate the relationship between the dependent variable, comfort with EOL conversations, and a set of confounding variables. Response choices for the dependent variable were combined into three groups for the analysis (1-2 uncomfortable; 3 neutral; 4-5 comfortable). Questions left blank and answer choices "not applicable", "not sure", or "prefer not to say" were excluded from the analysis. To test for potential nonresponder bias, we performed logistic regression analysis on responders versus non-responders using two known variables, department and gender, as covariates.

Of the original 33 survey questions, 21 were included in the multivariate logistic regression analysis. Reasons for exclusion from the analysis included: low response rate $(n=5)$, multiple selected combinations unable to be grouped $(n=4)$, highly correlated $(p<0.0001)$ with another question $(n=2)$, and descriptive text $(n=1)$. Of the questions excluded due to low response, all were follow-up questions, visible only to a subset of participants based on their previous answer choices. The final model was selected using stepwise selection procedure with 0.1 as the entry and stay probabilities for each variable. Only surveys with all answered questions were included in the stepwise selection procedure $(n=101)$.

\section{Results}

Of the 787 residents and fellows, 175 (22.2\%) participated in our voluntary survey. Residents from all 18 departmental specialties responded to our survey. There were more male participants $(58.9 \%)$ than female, which is consistent with our institutional demographics. The typical participant was Caucasian (72.1\%), US born (78.9\%) and between the ages of 25-34 (84.2\%). Approximately half identified themselves as Christian (50.7\%). Full demographic data is listed in Table 1. When testing for non-responder bias, no bias was identified for gender $(p=0.608)$, however, bias was found when looking at department $(p=0.003)$, suggesting some participants were more or less likely to respond to our survey based on their department of training.

Comfort with EOL conversations was gauged by asking the question, "At your current level of training, do you feel comfortable having end-of-life discussions with patients/families on your own?" (Table 2). The average comfort level having EOL conversations on a 5-point Likert scale was 3.90. The majority of participants (74.5\%) felt comfortable having EOL discussions. Only the minority were neutral $(11.7 \%)$ or uncomfortable (13.8\%) having these conversations.

We were very interested in the amount of formal education residents received on having EOL discussions. We asked participants to estimate the amount of time they spent in classroom training on having EOL discussions during medical school and residency (Table 3). Answer choices were: "None", "Very little (1-2 lectures)", "Some (1-2 week course or lecture series)", or "A Lot (>3 weeks)". We found that most residents reported very little to no training on EOL discussions in both medical school and residency (54.3\% and $88.1 \%$, respectively). 
Table 1 Demographics ${ }^{a}$

\begin{tabular}{|c|c|}
\hline Variable & Number (\%) \\
\hline \multicolumn{2}{|l|}{ Age in years } \\
\hline $20-24$ & $1(0.7 \%)$ \\
\hline $25-29$ & $42(28.8 \%)$ \\
\hline $30-34$ & $81(55.5 \%)$ \\
\hline $35-39$ & $15(10.3 \%)$ \\
\hline $40+$ & $7(4.8 \%)$ \\
\hline \multicolumn{2}{|l|}{ Gender } \\
\hline Male & $86(58.9 \%)$ \\
\hline Female & $60(41.1 \%)$ \\
\hline \multicolumn{2}{|l|}{ Race/Ethnicity } \\
\hline Caucasian/White & $106(72.1 \%)$ \\
\hline Black/African American & $3(2.0 \%)$ \\
\hline Hispanic/Latino & $8(5.4 \%)$ \\
\hline Asian & $26(17.7 \%)$ \\
\hline Pacific Islander/Hawaiian & $2(1.4 \%)$ \\
\hline Native American/Native Alaskan & $0(0.0 \%)$ \\
\hline Multiracial & $2(1.4 \%)$ \\
\hline \multicolumn{2}{|l|}{ Religious Affiliation } \\
\hline Christian & $74(50.7 \%)$ \\
\hline Muslim & $5(3.4 \%)$ \\
\hline Hindu & $11(7.5 \%)$ \\
\hline Buddhist & $0(0 \%)$ \\
\hline Jewish & $5(3.4 \%)$ \\
\hline Atheist & $8(5.5 \%)$ \\
\hline Agnostic & $18(12.3 \%)$ \\
\hline Other & $4(2.7 \%)$ \\
\hline Spiritual, but not religious & $27(18.5 \%)$ \\
\hline None & $5(3.4 \%)$ \\
\hline \multicolumn{2}{|l|}{ Place of birth } \\
\hline U.S. & $116(78.9 \%)$ \\
\hline Non-U.S. & $31(21.1 \%)$ \\
\hline \multicolumn{2}{|l|}{ Department } \\
\hline Internal Medicine & $35(27.1 \%)$ \\
\hline Surgery & $15(11.6 \%)$ \\
\hline Pediatrics & $12(9.3 \%)$ \\
\hline Anesthesiology & $12(9.3 \%)$ \\
\hline Family Medicine & $9(7.0 \%)$ \\
\hline Radiology & $7(5.4 \%)$ \\
\hline Neurosurgery & $5(3.9 \%)$ \\
\hline Radiation Oncology & $4(3.1 \%)$ \\
\hline Ophthalmology & $4(3.1 \%)$ \\
\hline Obstetrics and Gynecology & $4(3.1 \%)$ \\
\hline Pathology & $4(3.1 \%)$ \\
\hline Psychiatry & $4(3.1 \%)$ \\
\hline
\end{tabular}

Table 1 Demographics ${ }^{\mathrm{a}}$ (Continued)

\begin{tabular}{ll}
\hline Urology & $4(3.1 \%)$ \\
Orthopedic Surgery & $3(2.3 \%)$ \\
Emergency Medicine & $2(1.6 \%)$ \\
Neurology & $2(1.6 \%)$ \\
Dermatology & $2(1.6 \%)$ \\
Otolaryngology & $1(0.8 \%)$ \\
Post-graduate year & \\
PGY1-2 & $50(35.7 \%)$ \\
PGY 3-4 & $50(35.7 \%)$ \\
PGY 5+ & $40(28.6 \%)$ \\
Type of Medical School & \\
Allopathic (MD) & $113(77.9 \%)$ \\
Osteopathic (DO) & $8(5.5 \%)$ \\
International & $24(16.6 \%)$ \\
\hline
\end{tabular}

${ }^{\mathrm{a}}$ Missing variables not included

Only $45.7 \%$ of participants reported an adequate amount ("some" or "a lot") of EOL training during medical school; whereas this number fell to only $11.9 \%$ during residency.

We asked participants to estimate the number of times they had an EOL conversation during medical school and residency (Table 3). EOL conversations during medical school were relatively uncommon. A third of participants (33.1\%) had never had an EOL conversation during medical school and only 3.7\% reported having more than ten EOL conversations during medical school. The frequency of EOL conversations during residency increased; $50.6 \%$ reported more than ten conversations and only $6.7 \%$ reported never having had an EOL conversation.

Finally, participants were asked how much supervision they received while having EOL conversations with patients and their families (Table 3). Most (77.6\%) reported they were "always" or "mostly" supervised during medical school, however this fell to $38.1 \%$ during residency with the majority of residents (61.9\%) reporting their

Table 2 Comfort Question

Comfort with EOL discussions $n=145$

"At your current level of training, do you feel comfortable having endof-life discussions with patients/families on your own?"

Answer choices: ${ }^{a}$

Number(\%):

$5=\mid$ feel very comfortable

$47(32.4 \%)$

4 = | feel mostly comfortable

$61(42.1 \%)$

$3=$ I am neither comfortable nor uncomfortable $\quad 17$ (11.7\%)

$2=$ I am mostly uncomfortable $\quad 16(11.0 \%)$

1 = | feel very uncomfortable

$4(2.8 \%)$

"Answer choices "I'm not sure" and "other" were excluded from analysis 
Table 3 Education and Experience

\begin{tabular}{|c|c|}
\hline Question & Number (\%) \\
\hline \multicolumn{2}{|c|}{ Classroom training on EOL in medical school } \\
\hline None & $14(8.6 \%)$ \\
\hline Very Little & 75 (46.0\%) \\
\hline Some & $64(39.3 \%)$ \\
\hline A lot & $10(6.1 \%)$ \\
\hline \multicolumn{2}{|c|}{ Classroom training on EOL in residency } \\
\hline None & 59 (39.1\%) \\
\hline Very Little & $74(49.0 \%)$ \\
\hline Some & $17(11.3 \%)$ \\
\hline A lot & $1(0.7 \%)$ \\
\hline \multicolumn{2}{|c|}{ Number of EOL conversations in medical School } \\
\hline None & $53(33.1 \%)$ \\
\hline $1-5$ & $83(51.9 \%)$ \\
\hline $6-10$ & $18(11.3 \%)$ \\
\hline $11-15$ & $5(3.1 \%)$ \\
\hline $16-25$ & 0 \\
\hline $26-50$ & $1(0.6 \%)$ \\
\hline$>50$ & 0 \\
\hline \multicolumn{2}{|c|}{ Number of EOL conversations in residency } \\
\hline None & $10(6.7 \%)$ \\
\hline $1-5$ & $41(27.3 \%)$ \\
\hline $6-10$ & $23(15.3 \%)$ \\
\hline $11-15$ & $21(14.0 \%)$ \\
\hline $16-25$ & $21(14.0 \%)$ \\
\hline $26-50$ & $17(11.3 \%)$ \\
\hline$>50$ & $17(11.3 \%)$ \\
\hline \multicolumn{2}{|c|}{ EOL supervision in medical school } \\
\hline Always & $50(51.0 \%)$ \\
\hline Mostly supervised & $27(27.6 \%)$ \\
\hline Mostly unsupervised & $15(15.3 \%)$ \\
\hline Never & $6(6.1 \%)$ \\
\hline \multicolumn{2}{|c|}{ EOL supervision in residency } \\
\hline Always & $13(9.4 \%)$ \\
\hline Mostly supervised & $40(28.8 \%)$ \\
\hline Mostly unsupervised & $58(41.7 \%)$ \\
\hline Never & $28(20.1 \%)$ \\
\hline Not at all & $32(22.5 \%)$ \\
\hline \multicolumn{2}{|c|}{ Felt prepared for EOL after medical school } \\
\hline Not at all & $25(16.1 \%)$ \\
\hline A little & $59(38.1 \%)$ \\
\hline Somewhat & $50(32.3 \%)$ \\
\hline Very & $16(10.3 \%)$ \\
\hline Fully & 5 (3.2\%) \\
\hline
\end{tabular}

EOL conversations were "mostly unsupervised" or "never supervised".

To assess which factors may influence resident comfort with EOL conversations, we performed a multivariate logistic regression analysis. The questions analyzed fell into three categories: demographics, education/experience, and spirituality. All of the demographic variables (Table 1), including age, gender, race/ethnicity, religious affiliation, place of birth, department, postgraduate year and type of medical school, were included in the logistic regression; however, none of these were shown to influence physician comfort with EOL conversations. The questions relating to spirituality included belief in an afterlife $(n=1)$, fear of death $(n=1)$, and metaphysical experiences $(n=2)$. Similarly, none of these variables were found to correlate with resident comfort having EOL conversations.

In the education/experience category, we included all of the questions listed in Table 2 except supervision in medical school (eliminated due to low numbers). We did not find any statistically significant associations with classroom training during medical school, number of EOL conversations during medical school, or EOL supervision in residency. Three variables in the education/experience domain were found to have a strong association with comfort having EOL conversations and are listed in Table 4. These include the amount of classroom training on EOL discussions during residency (OR $=3.3$ (95\% CI: $1.2-8.9) ; p=0.017$ ), the number of EOL conversations during residency $(\mathrm{OR}=2.1$ (95\% CI: $1.3-$ $3.4) ; p=0.003$ ) and also how prepared the resident felt to have EOL conversations when graduating from medical school (OR $=2.1$ (95\% CI: 1.1-4.1); $p=0.030)$. Residents who reported greater classroom time on EOL care, had more EOL discussions, or felt more prepared to have EOL discussions when graduating from medical school were significantly more likely to feel comfortable having EOL discussions.

\section{Discussion}

Previous studies have shown that most physicians receive very little palliative care and EOL training during medical school and residency. In a study by Van AalstCohen, et al., only $30 \%$ of medical schools required education on hospice and palliative care [29]. Despite the recommendation by the Institute of Medicine that "educational institutions and professional societies provide training in palliative care domains throughout the professional's career," palliative care education remains underrepresented in medical school and residency curricula [11]. In the present study, over half of residents reported inadequate EOL education during medical school and nearly $90 \%$ reported inadequate education during residency. Although the low rate of EOL 
Table 4 Logistic regression analysis ${ }^{\mathrm{a}}$

\begin{tabular}{ll}
\hline Variable: & $\begin{array}{l}\text { Comfortable with EOL } \\
\text { conversations }^{\text {b }}\end{array}$ \\
\hline $\begin{array}{l}\text { Increased classroom training in } \\
\text { residency on EOL skills }\end{array}$ & $\begin{array}{l}\mathrm{OR}=3.3(95 \% \mathrm{Cl}: 1.2-8.9) ; \\
P=0.017\end{array}$ \\
$\begin{array}{l}\text { Felt more prepared after medical } \\
\text { school to have EOL conversations }\end{array}$ & $\begin{array}{l}\mathrm{OR}=2.1(95 \% \mathrm{Cl}: 1.1-4.1) ; \\
P=0.030\end{array}$ \\
$\begin{array}{l}\text { Higher numbers of EOL conversations } \\
\text { in residency }\end{array}$ & $\mathrm{OR}=2.1(95 \% \mathrm{Cl}: 1.3-3.4) ;$ \\
& $p=0.003$
\end{tabular}

${ }^{a}$ Only variables found to have statistically significant association with comfort are shown

${ }^{\mathrm{b}} \mathrm{OR}$ odds ratio, $\mathrm{Cl}$ confidence interval

education in residency may be specific to our institution, the low rates in medical school likely reflect a global problem of EOL care receiving little attention.

EOL conversations have been described as a medical procedure or skill [30]. Further supporting this idea, advanced care planning has recently been added as a billable procedure using current procedural terminology (CPT) codes. When viewed in this way, it is easy to understand why adequate training, experience and supervision are essential when learning how to have effective and timely EOL conversations. In this study, we demonstrate that many doctors graduate from medical school with very little experience or training having EOL conversations. During residency, these doctors receive very little additional preparation, yet are asked to lead EOL conversations often and unsupervised. Poor EOL conversation skills can strain the doctor-patient relationship, lead to unnecessary tests and procedures and result in higher healthcare costs and discomfort for patients.

EOL conversation skills can be taught. Multiple studies have demonstrated that EOL conversation training programs can be developed and implemented for medical students and residents and lead to improved conversation skills [31-34]. A recent meta-analysis published by Chung et al. found that educational interventions to improve EOL communication were associated with greater self-efficacy, more knowledge and improved communication scores [35]. Our findings are consistent with previous work and suggest that modifying educational programs to place greater emphasis on EOL care and communication can lead to greater comfort and skill in these areas.

Of the three domains we investigated as possibly influencing comfort with EOL care-physician demographics, spirituality and education/experience-we were only able to demonstrate a relationship between physician education/experience and comfort with EOL care. Previous studies have suggested that demographic variables such as physician race, age and specialty may influence hospice referral patterns $[12,28,36]$. The relatively young age, lack of minority representation and small sample size of our study may have caused small differences to be missed. Likewise, previous studies have shown that physician religion and spirituality may also influence care, [37-39] although this was not appreciated in the present study. More research on the influence of physician attitudes and beliefs on patient care is needed.

Limitations of this study are inherent in its design as a survey. There may be recall bias as accurate assessment of classroom training, number of EOL conversations and degree of supervision relies on memory and may not be reflective of the actual experience of these resident physicians. This survey was conducted at a single institution and only included residents/fellows in training, and therefore may not be generalizable to all institutions or all physicians or residents. As noted previously, we did find bias with some departments being over- and underrepresented in our study. Residents were aware of the nature of the survey prior to participating, which may have led to selection bias towards physicians interested in this topic. The survey was voluntary and our response rate was low $(22.2 \%)$, which also threatens the validity of the study.

Another limitation in the study was that we did not confirm the amount of EOL education that was actually given to residents in the various departments. It is possible that those who feel uncomfortable with EOL conversations are receiving the same amount of education, but are less likely to recall the lectures they received. Although we know from prior studies that comfort with EOL care correlates with hospice referral among physicians, this was not addressed in the present study. Additional research is needed to investigate how palliative care educational programs may influence the long-term practice patterns of physicians.

\section{Conclusion}

Resident education in EOL care is associated with enhanced comfort with EOL conversations. By increasing the amount of formal training and supervision, especially during residency, physician comfort may improve, leading to earlier and more appropriate hospice referrals, better end-of-life care and improved quality-of-life for our terminal patients. Palliative care and EOL discussions should be included as an additional communication milestone when the next iteration of the Milestone Project by the Accreditations Council for Graduate Medical Education (ACGME) and American Board of Medical Specialties (ABMS) specialty boards is developed.

\section{Additional file}

Additional file 1: Physician Perspectives on Death and Dying. (DOCX 20 kb)

Acknowledgements

None. 


\section{Funding}

No source of funding for this study.

\section{Availability of data and materials}

Raw data has not been made publically available to protect anonymity of the participants. Data is available from the authors upon request.

\section{Authors' contributions}

JMS, LEM, JMD and JLC contributed to the design and implementation of the survey. LEM, YD and FZ performed the statistical analysis. JMS wrote the manuscript. All authors contributed to the preparation of the final manuscript.

\section{Competing interests}

The authors declare that they have no competing interests.

\section{Consent for publication}

Not applicable.

\section{Ethics approval and consent}

The University of Florida's Institutional Review Board approved the design of the study. A copy of the informed consent was provided to all residents via electronic mail. Participants were asked to read the informed consent prior to proceeding to the electronic survey.

\section{Author details}

${ }^{1}$ Department of Medicine, Division of Hematology and Oncology, University of Florida, 1600 SW Archer Rd, 32610 Gainesville, FL, USA. ${ }^{2}$ College of Medicine, Office of Graduate Medical Education, University of Florida, Gainesville, FL, USA. ${ }^{3}$ Department of Biostatistics, University of Florida, Gainesville, FL, USA.

Received: 15 June 2016 Accepted: 8 November 2016 Published online: 21 November 2016

\section{References}

1. Bakitas MA, Tosteson TD, Li Z, et al. Early versus delayed initiation of concurrent palliative oncology care: Patient outcomes in the ENABLE III randomized controlled trial. J Clin Oncol. 2015;33:1438-45.

2. Temel JS, Greer JA, Admane S, et al. Longitudinal perceptions of prognosis and goals of therapy in patients with metastatic non-small-cell lung cancer: Results of a randomized study of early palliative care. J Clin Oncol. 2011;29:2319-26.

3. Connor SR, Pyenson B, Fitch $\mathrm{K}$, et al. Comparing hospice and nonhospice patient survival among patients who die within a 3-year window. J Pain Symptom Manage. 2007:33:238-46.

4. Brumley R, Enguidanos S, Jamison P, et al. Increased satisfaction with care and lower costs: Results of a randomized trial of in-home palliative care. J Am Geriatr Soc. 2007:55:993-1000.

5. Gade G, Venohr I, Conner D, et al. Impact of an inpatient palliative care team: A randomized control trial. J Palliat Med. 2008:11:180-90.

6. Emanuel EJ, Ash A, Yu W, et al. Managed care, hospice use, site of death, and medical expenditures in the last year of life. Arch Intern Med. 2002;162:1722-8.

7. Wright AA, Zhang B, Ray A, et al. Associations between end-of-life discussions, patient mental health, medical care near death and caregiver bereavement adjustment. JAMA. 2008;300:1665-73.

8. Sun V, Grant M, Koczywas M, et al. Effectiveness of an interdisciplinary palliative care intervention for family caregivers in lung cancer. Cancer 2015:121:3737-45

9. Ferrell B, Sun V, Hurria A, et al. Interdisciplinary palliative care for patients with lung cancer. J Pain Symptom Manage. 2015:50:758-67.

10. Bakitas M, Lyons KD, Hegel MT, et al. Effects of a palliative care intervention on clinical outcomes in patients with advanced caner: The Project ENABLE I randomized controlled trial. JAMA. 2009:302:741-9.

11. Institute of Medicine. Dying in America: Improving quality and honoring individual preferences near the end of life. Washington, DC: National Academies Press; 2014

12. Bradley EH, Cramer LD, Bogardus Jr ST, et al. Physicians' ratings of thei knowledge, attitudes, and end-of-life-care practices. Acad Med. 2002;77:305-11.

13. Berry DE, Boughton L, McNamee F. Patient and physician characteristics affecting the choice of home based hospice, acute care inpatient hospice facility or hospitals as last site of care for patients with cancer of the lung Hosp J. 1994:9:21-38.

14. McGorty EK, Bornstein BH. Barriers to physicians' decisions to discuss hospice: Insights gained from the United States hospice model. J Eval Clin Pract. 2003:9:363-72

15. Weeks JC, Cook EF, O'Day SJ, et al. Relationship between cancer patients' predictions of prognosis and their treatment preferences. JAMA. 1998;279:1709-14.

16. Ogle KS, Mavis B, Wyatt GK. Physicians and hospice care: Attitudes, knowledge, and referrals. J Palliat Med. 2002;5:85-92

17. Garrett JM, Harris RP, Norburn JK, et al. Life-sustaining treatments during terminal illness: Who wants what? J Gen Intern Med. 1993;8:361-8.

18. Miesfeldt S, Murray K, Lucas L, et al. Association of age, gender, and race with intensity of end-of-life care for medicare beneficiaries with cancer. J Palliat Med. 2012;15:548-54.

19. Caralis $P$, Davis $B$, Wright $K$, Marcial E. The influence of ethnicity and race on attitudes toward advance directives, life-prolonging treatments and euthanasia. J Clin Ethics. 1993;4:155-65.

20. Greiner KA, Perera S, Ahluwalia JS. Hospice usage by minorities in the last year of life: Results from the National Mortality Followback Survey. J Am Geriatr Soc. 2003;56:1953-8.

21. Brickner L, Scannell K, Marquet S, Ackerson L. Barriers to hospice care and referrals: survey of physicians' knowledge, attitudes, and perceptions in a health maintenance organization. J Palliat Med. 2004;7:411-8.

22. Rhymes J. Hospice care in America. JAMA. 1990;264:369-72.

23. Sullivan AM, Lakoma MD, Matsuyama RK, et al. Diagnosing and discussing imminent death in the hospital: A secondary analysis of physician interviews. J Palliat Med. 2007:10:882-92.

24. Ogle K, Mavis B, Wang T. Hospice and primary care physicians: Attitudes, knowledge, and barriers. Am J Hosp Palliat Care. 2003;20:41-51.

25. Weggel JM. Barriers to the physician decision to offer hospice as an option for terminal care. WMJ. 1999;98:49-53.

26. Snow CE, Varela BR, Pardi DA, et al. Identifying factors affecting utilization of an inpatient palliative care service: A physician survey. J Palliat Med. 2009;12:231-7.

27. Brown AJ, Shen MJ, Ramondetta LM, et al. Does death anxiety affect end-oflife care discussions? Int J Gynecol Cancer. 2014;24:1521-6.

28. Kogan AC, Brumley R, Wilber K, Enquidanos S. Physician factors that influence patient referrals to end-of-life care. Am J Manag Care. 2012;18:e416-22.

29. Van Aalst-Cohen ES, Riggs R, Byock IR. Palliative care in medical school curricula: A survey of United States medical schools. J Palliat Med. 2008;11:1200-2.

30. Meyer DE. Palliative Care and the human connection: Ten steps for what to say and do Video file]. CAPC Palliative. 2013. https://youtu.be/ 7kQ3PUyhmPQ. Accessed 13 Sept 2016.

31. Alexander SC, Keitz SA, Sloane R, Tulsky JA. A controlled trial of a short course to improve residents' communication with patients at the end of life Acad Med. 2006:81:1008-12.

32. Back AL, Arnold RM, Tulsky JA, et al. Teaching communication skills to medical oncology fellows. J Clin Oncol. 2003;21:2433-6.

33. Fallowfield L, Jenkins V, Farewell V, et al. Efficacy of a Cancer Research UK communication skills training model for oncologists: A randomized controlled trial. Lancet. 2002;359:650-6.

34. Seoane $\mathrm{L}$, Bourgeois DA, Blais CM, et al. Teaching palliative care in the intensive care unit: How to break the news. Ochsner J. 2012:12:312-7.

35. Chung HO, Oczkowski SJ, Hanvey L, Mbuagbaw L, You JJ. Educational interventions to train healthcare professionals in end-of-life communication: a systematic review and meta-analysis. BMC Med Educ. 2016;16:131.

36. Mebane EW, Oman RF, Kroonen LT, Goldstein MK. The influence of physician race, age and gender on physician attitudes towards advanced care directives and preferences for end-of-life decision-making. J Am Geriatr Soc. 1999;47:579-91.

37. Bulow $\mathrm{HH}$, Sprung $\mathrm{CL}$, Baras $\mathrm{M}$, et al. Are religion and religiosity important to end-f-life decisions and patient autonomy in the ICU? The Ethicatt study. Intensive Care Med. 2012:38:1126-33.

38. Curlin FA, Chin MH, Sellergren SA, Roach CJ, Lantos JD. The association of physicians' religious characteristics with their attitudes and self-reported behaviors regarding religion and spirituality in the clinical encounter. Med Care. 2006:44:446-53.

39. Wenger NS, Carmel S. Physicians' religiosity and end-of-life care attitudes and behaviors. Mt Sinai J Med. 2004;71:335-43. 